\title{
Miniaturized Microstrip Patch Antenna with Defected Ground Structure
}

\author{
Hanae Elftouh $^{1,}{ }^{*}$, Naima A. Touhami ${ }^{1}$, Mohamed Aghoutane ${ }^{1}$, \\ Safae El Amrani ${ }^{1}$, Antonio Tazon ${ }^{2}$, and Mohamed Boussouis ${ }^{1}$
}

\begin{abstract}
The aim of this work is to miniaturize a microstrip patch antenna resonating at $3 \mathrm{GHz}$. For this purpose, defected ground structure (DGS) has been employed to shift the resonance frequency of an initial microstrip antenna from $5.7 \mathrm{GHz}$ to $3 \mathrm{GHz}$ by disturbing the antenna's current distribution. The proposed DGS is incorporated in the ground plane under the patch antenna to improve its performances. Finally, a miniaturization up to $50 \%$, with respect to the conventional microstrip antenna, is successfully accomplished. A prototype of the antenna was fabricated with the FR4 substrate and tested. The measurements results were in good agreement with simulation results.
\end{abstract}

\section{INTRODUCTION}

Microstrip patch antennas have been a topic of intense investigation over the last two decades, due to their several advantages and better prospects [1]. Among these advantages we distinguish for instance: lighter weight, lower cost and smaller dimensions. Moreover, microstrip patch antennas can be easily designed to operate in dual-band and multi-band applications, for dual or circular polarization [2]. Thus, they are widely used in many practical applications such as medical applications, satellites and military systems [3].

With the rapid development in wireless communications, much effort has been devoted to reduce the size of microstrip antennas. In this way, several methods have been proposed recently [4], such as using a dielectric substrate of high permittivity [5], Defected Microstrip Structure (DMS) [6], Defected Ground Structure (DGS) at the ground plane [7] or a combination of them.

Mainly DGS is a periodic or non-periodic cascaded defect configuration etched in the ground plane of a planar transmission line. The defect geometry is easy to implement and does not need a large area. These features enable such structures to acquire a great relevance in microwave circuit design [8]. In particular, DGS is employed to design microstrip antennas for different applications, as for instance, cross polarization, mutual coupling reduction in antenna arrays and harmonic suppression. Moreover, DGS has been widely used in the development of miniaturized antennas [9].

When DGS is introduced in a microstrip antenna, the defect geometry etched in the ground plane disturbs its current distribution [10,11]. This disturbance affects the transmission line characteristics, such as the line capacitance and inductance. In other words, introducing DGS in a microstrip antenna can result in an increase of the effective capacitance and inductance [12] which influences the input impedance and current flow of the antenna $[13,14]$ and thus reducing its size with respect to a given resonance frequency.

In this paper, we use DGS to design a miniaturized microstrip antenna as compared with a conventional one, resonating at $3 \mathrm{GHz}$ [15]. Initially the proposed antenna resonates at $5.7 \mathrm{GHz}$, and then DGS is employed to shift the resonance frequency to $3 \mathrm{GHz}$. Finally, a comparison between our DGS microstrip antenna and the conventional one, at $3 \mathrm{GHz}$, is carried out.

Received 23 September 2014, Accepted 13 November 2014, Scheduled 18 November 2014

* Corresponding author: Hanae Elftouh (elftouhhanae@hotmail.fr).

1 Faculty of Science, University Abdelmalek Essaidi, Tetouan, Morocco. ${ }^{2}$ University of Cantabria, Spain. 


\section{MICROSTRIP PATCH ANTENNA RESONATING AT $5.7 \mathrm{GHz}$}

The proposed microstrip patch antenna is shown in Fig. 1. For improved adaptation, one U-shaped slot and two cuts are introduced on the patch. In this design the substrate FR4 is used due to its low cost and easy fabrication. The substrate height is $1.6 \mathrm{~mm}$, the dielectric constant is 4.4 and the loss tangent is 0.021. The dimensions of our antenna are optimized by using CST Microwave Studio tool.

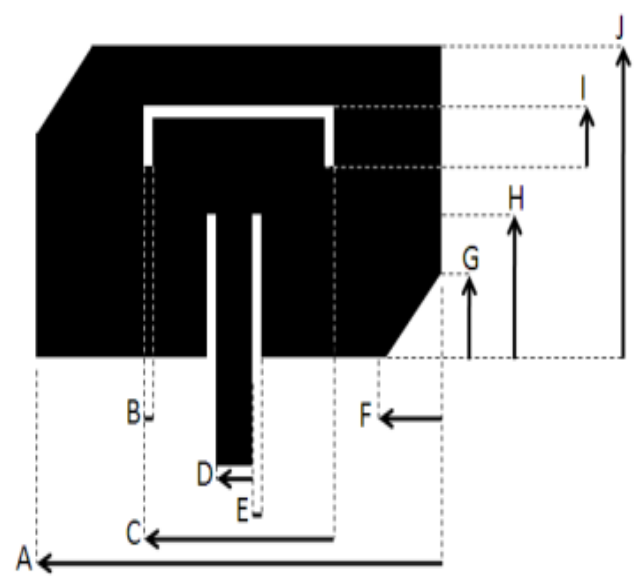

Figure 1. Top view of our patch antenna resonating at $5.7 \mathrm{GHz},(A=13 \mathrm{~mm}, B=0.2 \mathrm{~mm}$, $C=6.6 \mathrm{~mm}, D=2 \mathrm{~mm}, E=0.3 \mathrm{~mm}, F=$ $2 \mathrm{~mm}, G=2 \mathrm{~mm}, H=3 \mathrm{~mm}, I=3 \mathrm{~mm}$ and $J=12 \mathrm{~mm}$ ).

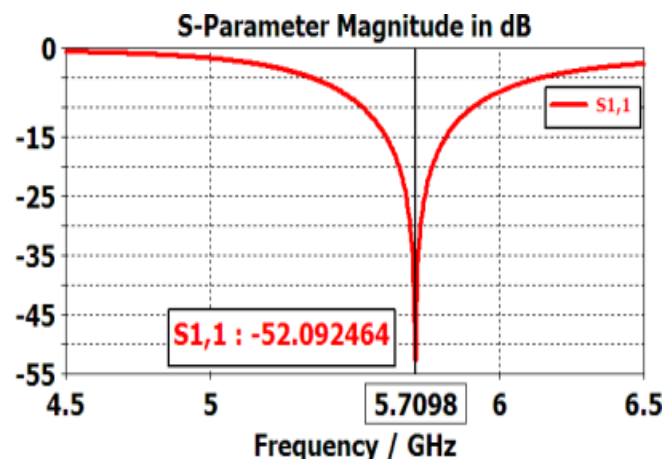

Figure 2. Simulated return loss of the patch antenna resonating at $5.7 \mathrm{GHz}$.

The simulated return loss obtained for this antenna is shown in Fig. 2. We can see that the adaptation is better than $10 \mathrm{~dB}$ in a frequency band of about $200 \mathrm{MHz}$ and the resonance frequency is around $5.7 \mathrm{GHz}$.

\section{DEFECTED GROUND STRUCTURE (DGS)}

Recently, there has been an increasing interest in the study of microstrip lines with various periodic structures that prohibit wave propagation in certain frequency bands, including photonic band gap (PBG), electromagnetic band gap (EBG) and defected ground structures (DGSs) [16]. Fig. 3 shows

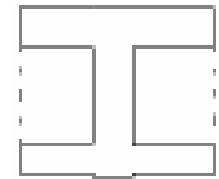

(a)

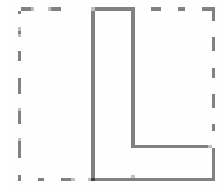

(f)

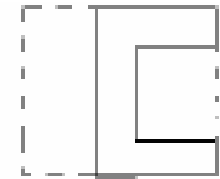

(b)

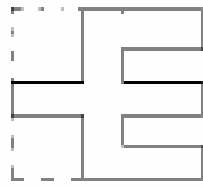

(g)

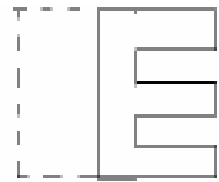

(c)

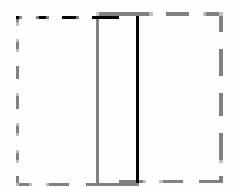

(h)

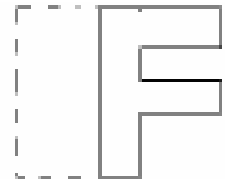

(d)

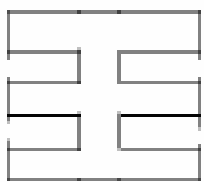

(i)

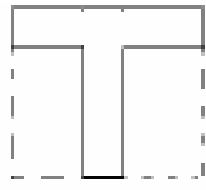

(e)

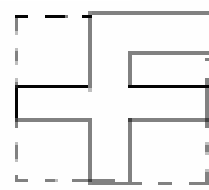

(j)

Figure 3. Different geometries of DGS. 


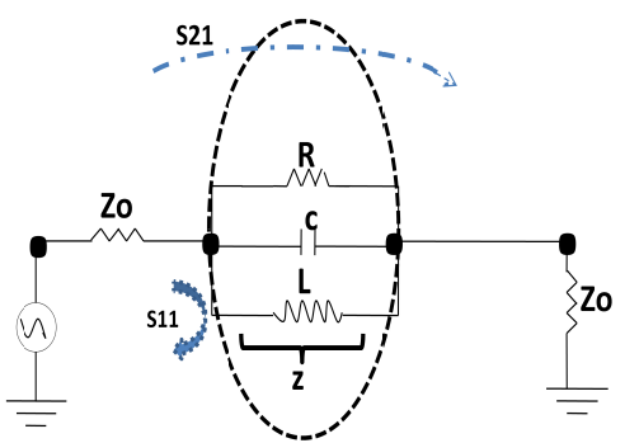

Figure 4. Equivalent circuit of DGS.

some of the DGS geometries used, which may be simple or relatively more complicated.

In general, the equivalent circuit of a DGS consists of a parallel tuned circuit in series with the transmission line to which it is coupled [17], as shown in Fig. 4.

The varieties of attached area shapes have the same role and the same characteristics of miniaturization of size, stop band, slow wave effect and high impedance [12-14]. And also they all have the same equivalent circuit. However, we change the kind of DGS only to improve the circuit performance of each antenna.

In our model, radiation and surface wave losses were taken into consideration by including the parallel resistance $R$ in the equivalent circuit.

The equivalent admittance of the parallel resonance is given by Equation (1):

$$
Y=\frac{1}{R}+j 2 \pi\left(C f-\frac{1}{4 \pi^{2} L f}\right)
$$

Since $Z=1 / Y$, then the equivalent impedance is given by

$$
Z=1 / \frac{1}{R}+j 2 \pi\left(C f-\frac{1}{4 \pi^{2} L f}\right)
$$

In order to compute the equivalent circuit parameters $(R, L$, and $C)$, we use the following expressions [18]:

$$
\begin{aligned}
S_{21} & =\frac{1}{1+\frac{1}{2} Z Z_{0}^{-1}} \\
S_{21} & =\frac{2 Z_{0}}{2 Z_{0}+\left[\frac{1}{R}+j 2 \pi\left(C f-\frac{1}{4 \pi^{2} L f}\right)\right]^{-1}}
\end{aligned}
$$

Supposing that $R \gg Z_{0}$, we obtain:

$$
S_{21}=\frac{2 Z_{0}}{2 Z_{0}+\left[j 2 \pi\left(C f-\frac{1}{4 \pi^{2} L f}\right)\right]^{-1}}
$$

At $-3 \mathrm{~dB}$ corresponding to the cutoff frequency $f_{c}$ we have:

$$
\left|S_{21}\right|=\frac{2 Z_{0}}{\sqrt{4 Z_{0}^{2}+\left(\frac{\omega_{c}}{C\left(\omega_{0}^{2}-\omega_{c}^{2}\right)}\right)^{2}}}=\frac{1}{\sqrt{2}}
$$

where $\omega_{c}$ is the cutoff angular frequency and $\omega_{0}$ is the resonance angular frequency.

\section{Reproduced courtesy of The Electromagnetics Academy}



circuit:

Using Equations (5) and (6), we conclude the capacitance and the inductance of the equivalent

$$
\begin{aligned}
& C=\frac{\omega_{c}}{2 Z_{0}\left(\omega_{0}^{2}-\omega_{c}^{2}\right)} \\
& L=\frac{2 Z_{0}\left(\omega_{0}^{2}-\omega_{c}^{2}\right)}{\omega_{c} \omega_{0}^{2}}
\end{aligned}
$$

Resistance $R$ in the equivalent circuit is best fitted around the resonance frequency. In this case, the equivalent impedance $Z_{e}=R$ and then we have:

$$
\left.S_{21}\right|_{\omega=\omega_{0}}=\left|\frac{2 Z_{0}}{2 Z_{0}+Z_{e}}\right|=\frac{2 Z_{0}}{2 Z_{0}+R}
$$

Then,

$$
R=\frac{2 Z_{0}\left(1-S_{21 \mid \omega=\omega_{0}}\right)}{S_{21 \mid \omega=\omega_{0}}}
$$

\section{MICROSTRIP PATCH ANTENNA WITH DGS}

We introduce DGS in order to shift the resonance frequency of the microstrip antenna previously presented in Fig. 1. First we introduce one cell of the selected DGS geometry and we study its effect on the antenna properties, specially the resonance frequency. Then we introduce a second cell of DGS and do the same study. Both of these simulations have been carried out by CST Microwave Studio.

\subsection{With One Cell of DGS}

One cell of the selected DGS geometry is etched on the metallic ground plane of our antenna as shown in Fig. 5.

In absence of DGS, we have seen in Section 2 that the resonance frequency of our microstrip patch antenna is at $5.7 \mathrm{GHz}$. Now with one cell DGS introduced, the simulation result obtained for the return loss is shown in Fig. 6. We can see that the resonance frequency has been significantly influenced by the DGS, namely, it has been brought to about $3.38 \mathrm{GHz}$.

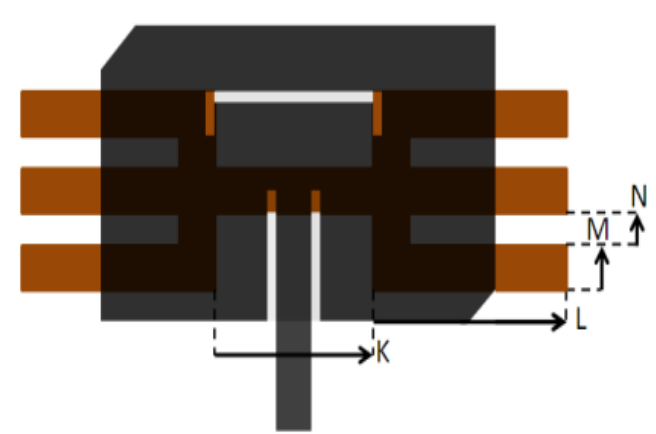

Figure 5. Microstrip patch antenna with one cell DGS $(K=11.5 \mathrm{~mm}, L=4 \mathrm{~mm}, M=0.7 \mathrm{~mm}$ and $N=0.5 \mathrm{~mm})$.

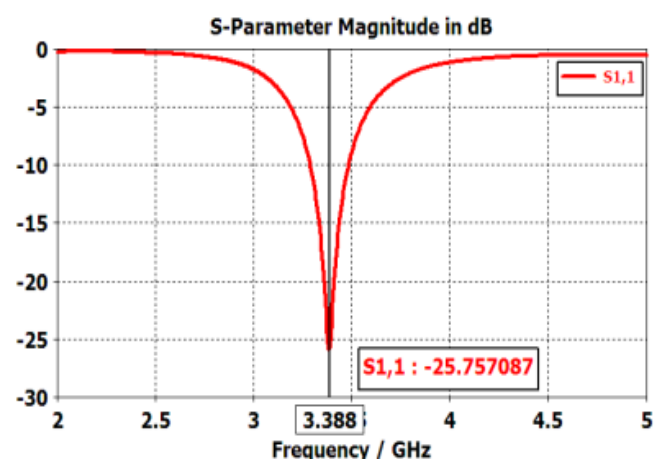

Figure 6. Simulation of return loss for the antenna with one cell of DGS.

\subsection{With Two Cells of DGS}

Now we introduce the second cell of DGS to our proposed antenna as shown in Fig. 7.

\section{Reproduced courtesy of The Electromagnetics Academy}




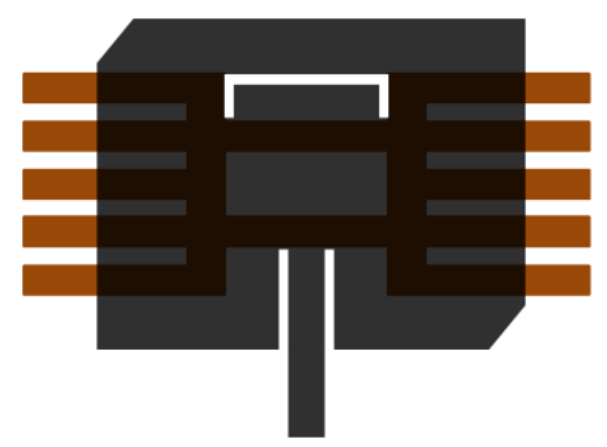

Figure 7. Microstrip antenna with two cells of DGS.

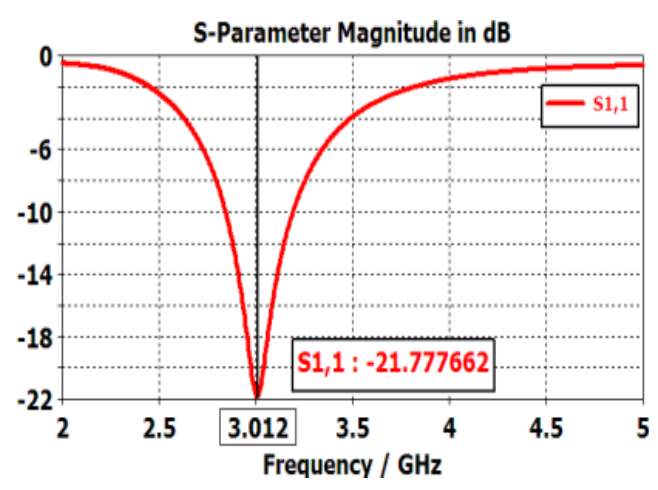

Figure 8. Simulation of return loss for the antenna with two cells of DGS.

With two DGS of cells, the return loss simulation result presented in Fig. 8 shows that the resonance frequency has been shifted to around $3 \mathrm{GHz}$.

Thus, we can say that we have obtained very acceptable result with simulation. Namely, we have designed a microstrip patch antenna with DGS resonating at $3 \mathrm{GHz}$. Next we present our antenna fabrication and compare simulation with measurement results.

\section{FABRICATION AND MEASUREMENT}

We have fabricated a prototype of our microstrip patch antenna for each case: one cell and two cells of DGS. We have used an FR4 substrate with relative dielectric constant 4.3 and thickness $1.58 \mathrm{~mm}$. Fig. 9 shows the size of the fabricated DGS microstrip antenna that operates at $3.38 \mathrm{GHz}$ with one cell

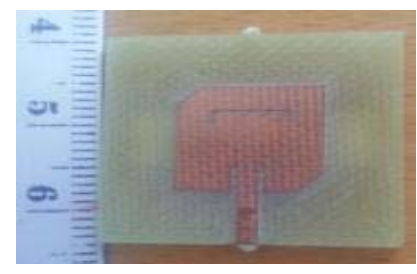

(a)

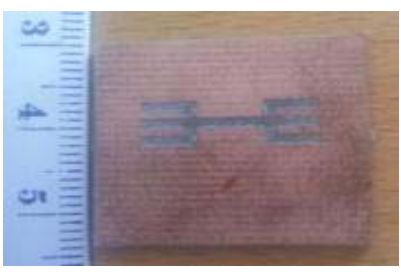

(b)

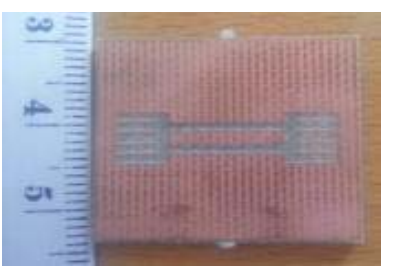

(c)

Figure 9. Prototype of DGS microstrip antenna, (a) top view, (b) bottom view with one cell of DGS, (c) bottom view with two cells of DGS.

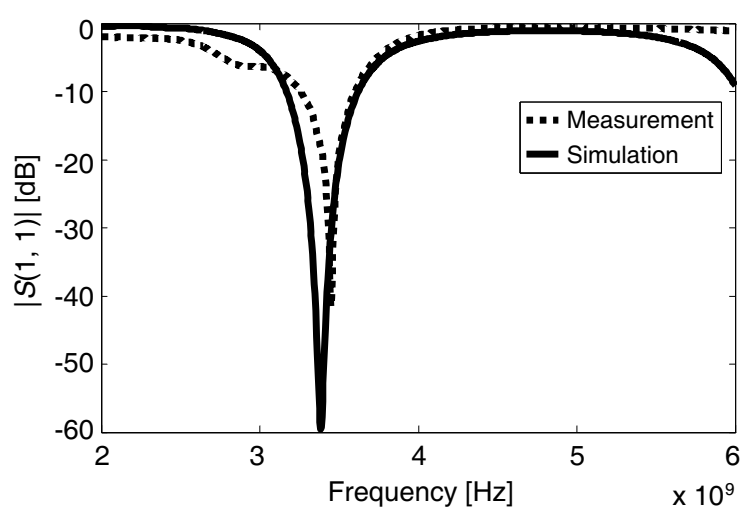

Figure 10. Measurement and simulation results for the antenna with one cell of DGS (resonating at $3.38 \mathrm{GHz}$ ).

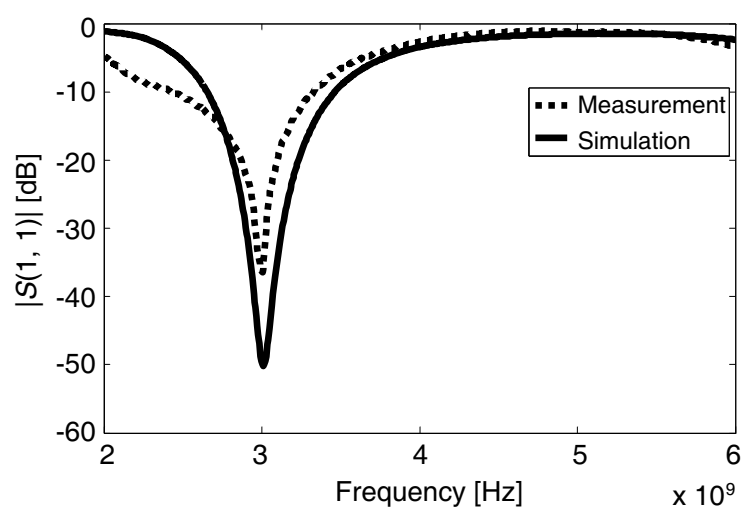

Figure 11. Measurement and simulation results for the antenna with two cells of DGS (resonating at $3 \mathrm{GHz}$ ).

\section{Reproduced courtesy of The Electromagnetics Academy}


of DGS and at $3 \mathrm{GHz}$ with two cells of DGS.

In order to measure the scattering parameters of the proposed antenna, we have been employing a Rohde and Schwarz ZVB 20 vector network analyzer, which frequency range is limited to $20 \mathrm{GHz}$. Thus, the $S_{11}$ parameter was measured and compared to the simulated results.

Figures 10 and 11 show the comparison between measurement and simulation results of the microstrip patch antenna with one cell and two cells of DGS, respectively. We can see that there is a good agreement between simulation and measurement results near the resonance frequency in both cases.

\section{COMPARISON BETWEEN CONVENTIONAL ANTENNA AND ANTENNA WITH DGS AT 3 GHz}

\subsection{Size Comparison}

Figure 12 shows a size comparison between a conventional microstrip antenna and the antenna that we have previously designed using two cells of DGS, and both resonating at $3 \mathrm{GHz}$. We can see that employing a defected ground plane beneath the microstrip patch antenna allows us to reduce the conventional surface up to $50 \%$.

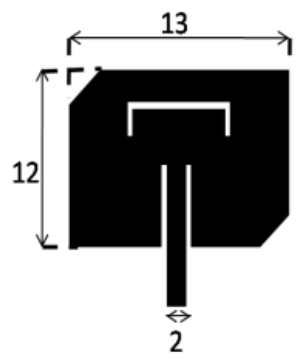

(a)

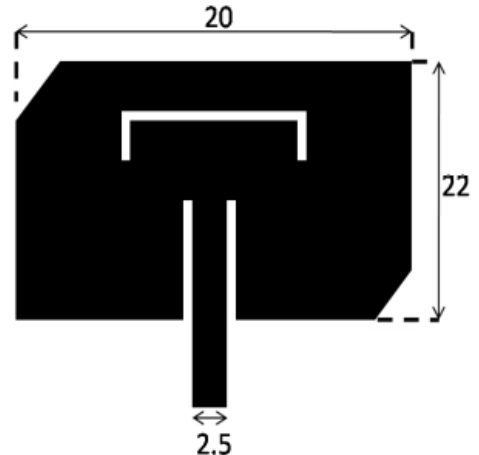

(b)

Figure 12. Top view dimensions ( $\mathrm{mm}$ ) for the $3 \mathrm{GHz}$ antennas, (a) antenna with DGS, (b) conventional antenna.

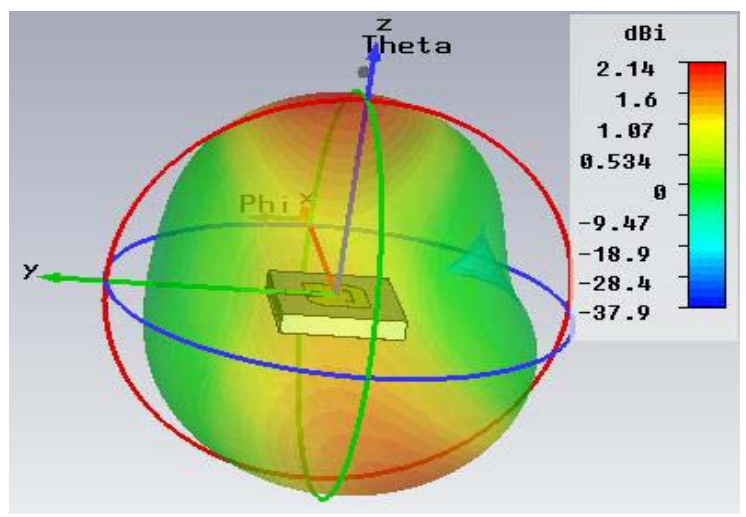

Figure 13. Radiation pattern for the DGS antenna.

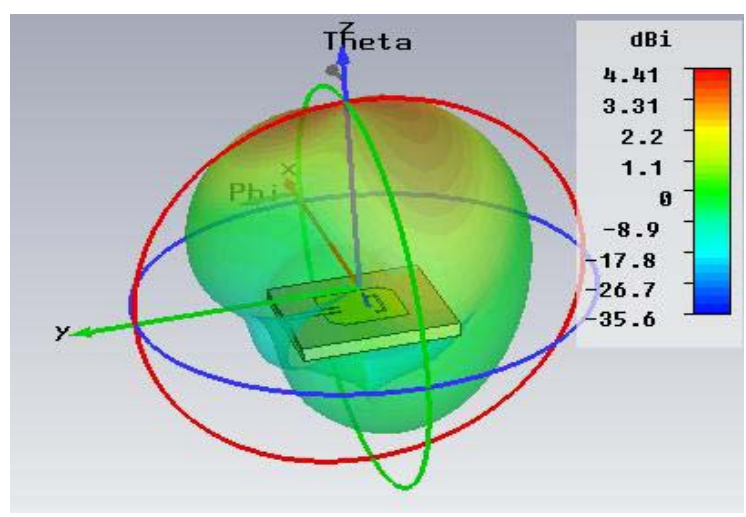

Figure 14. Radiation pattern for the conventional antenna. 


\subsection{Radiation Pattern}

The radiation patterns presented in Figs. 13 and 14 are obtained for our DGS microstrip antenna and for a conventional microstrip antenna at $3 \mathrm{GHz}$, respectively. In these figures we can see that the simulated gain for the DGS antenna is $2.14 \mathrm{dBi}$ as for the conventional antenna the simulated gain is $4.41 \mathrm{dBi}$.

With DGS in the ground plane, the antenna will radiate on both sides of the ground plane due to the aperture efficiency resulting in a high back radiation level which explain the gain reduce about $2 \mathrm{~dB}$. This gain decrease is explained by the increase of lateral and longitudinal radiations due to the propagation of surface waves. Namely, these radiations adversely affect the main lobe power, and therefore a reduction of the gain is produced (see Figs. 13 and 14). In fact, one of the problems in microstrip antenna applications is to reduce the size while keeping good performance.

\subsection{Current Distribution}

To further examine the excitation mechanism, average surface current distributions obtained from CST simulation on both patch and ground plane for optimized antenna were studied. Figs. 15 and 16, show the current distribution of patch antenna without and with DGS respectively at $3 \mathrm{GHz}$. In conventional antenna, a large surface current was observed over the coins of the patch and along the microstrip line (Fig. 15). However, the current was more concentrated along the DGS on the ground plane of the patch antenna (Fig. 16). The defects on ground structure disturbs the current distribution, resulting in a controlled excitation and propagation of the electromagnetic waves via the substrate layer and change the resonance peak.

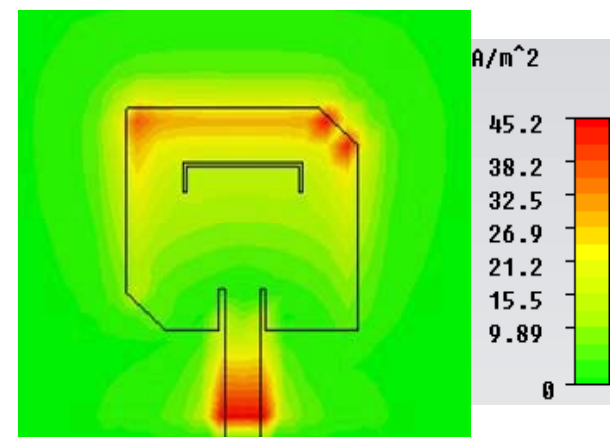

Figure 15. The current distribution of conventional antenna at $3 \mathrm{GHz}$.

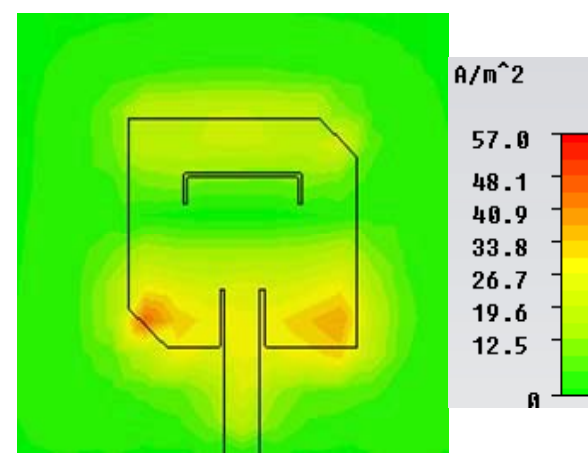

(a)

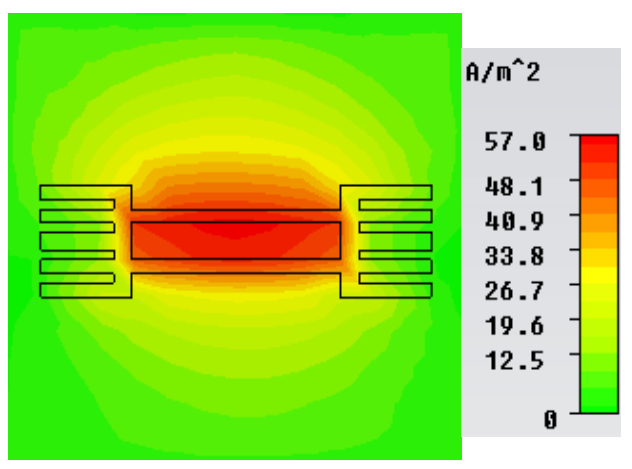

(b)

Figure 16. The current distribution of patch antenna at $3 \mathrm{GHz}$, (a) front view, (b) back view.

\section{Reproduced courtesy of The Electromagnetics Academy}




\section{CONCLUSION}

We have carried out the design of a miniaturized microstrip patch antenna with defected ground structure resonating at $3 \mathrm{GHz}$. The resonance frequency of the initial antenna (without DGS) has been shifted from $5.7 \mathrm{GHz}$ to $3 \mathrm{GHz}$ after introducing DGS. In this way, we have been able to reduce the antenna size up to $50 \%$ as compared with a conventional microstrip antenna resonating at the same frequency $(3 \mathrm{GHz})$.

\section{ACKNOWLEDGMENT}

The authors would like to thank the Department of Engineering of Communications, University of Cantabria.

\section{REFERENCES}

1. Howell, J. Q., "Microstrip antennas," Dig. Int. Symp. Antennas Propagat. Soc., 177-180, Williamsburg, VA, Dec. 1972.

2. Liu, J., W.-Y. Yin, and S. He, "A new defected ground structure and its application for miniaturized switchable antenna," Progress In Electromagnetic Research, Vol. 107, 115-128, 2010.

3. Arya, A. K., A. Patnaik, and M. V. Kartikeyan, "Gain enhancement of micro-strip patch antenna using dumbbell shaped defected ground structure," International Journal of Scientific Research Engineering \& Technology (IJSRET), Vol. 2, No. 4, 184-188, Jul. 2013.

4. Nashaat, D., H. A. Elsade, E. Abdallah, H. Elhenawy, and M. F. Iskandar, "Multiband and miniaturized inset feed microstrip patch antenna using multiple spiral-shaped defect ground structure (DGS)," IEEE Antennas and Propagation Society International Symposium, 2009, APSURSI'09, 1-4, Jun. 1-5, 2009.

5. Lo, T. K. and Y. Hwang, "Microstrip antennas of very high permittivity for personal communications," 1997 Asia Pacific Microwave Conference, 253-256, 1997.

6. Tirado-Mendez, J. A., M. A. Peyrot-Solis, H. Jardon-Aguilar, E. A. Andrade-Gonzalez, and M. Reyes-Ayala, "Applications of novel defected microstrip structure (DMS) in planar passive circuits," Proceedings of the 10th WSEAS International Conference on CIRCUITS, 336-369, Vouliagmeni, Athens, Greece, Jul. 10-12, 2006.

7. Chakraborty, M., B. Rana, P. P. Sarkar, and A. Das, "Size reduction of microstrip antenna with slots and defected ground structure," International Journal of Electronics Engineering, Vol. 4, No. 1, 61-64, 2012.

8. Elsheakh, D. M., H. A. Elsadek, E. A.-F. Abdallah, H. M. Elhenawy, and M. F. Iskander, "Miniaturized and multiband operations of inset feed microstrip patch antenna by using novel shape of defected ground structure (DGS) in wireless applications," PIERS Proceeding, 1082-1086, Moscow, Russia, Aug. 18-21, 2009.

9. Kim, H. M. and B. Lee, "Bandgap and slow fast-wave characteristics of defected ground structures (DGSs) including left-handed features," IEEE Trans. Microwave Theory Techn., Vol. 54, No. 7, 3113-3120, 2006.

10. Arya, A. K., M. V. Kartikeyan, and A. Patnaik, "Efficiency enhancement of microstrip patch antennas with defected ground structure," Proc. IEEE Recent Advanced in Microwave Theory and Applications (MICROWAVE-08), 729-731, Nov. 2008.

11. Zulkifli, F. Y., E. T. Rahardjo, and D. Hartanto, "Mutual coupling reduction using dumbbell defected ground structure for multiband microstrip antenna array," Progress In Electromagnetics Research Letters, Vol. 13, 29-40, 2010.

12. Fan, M., R. Hu, Z. H. Feng, X. X. Zhang, and Q. Hao, "Advance in 2D-EBG structures research," The Journal of Infrared and Millimeter Waves, Vol. 22, No. 2, 2003.

13. Arya, A. K., A. Patnaik, and M. V. Kartikeyan, "Microstrip patch antenna with skew-F shaped DGS for dual band operation," Progress In Electromagnetics Research M, Vol. 19, 147-160, 2011.

\section{Reproduced courtesy of The Electromagnetics Academy}


14. Kapoor, S. and D. Parkash, "Miniaturized triple band microstrip patch antenna with defected ground structure for wireless communication applications," International Journal of Computer Applications, Vol. 57, No. 7, ISSN: 0975-8887, Nov. 2012.

15. Pozar, D. M., "Microstrip antennas," Proceedings of the IEEE, Vol. 80, No. 1, 79-91, Jan. 1992.

16. Rahman, M. and M. A. Stuchly, "Transmission line-periodic circuit representation of planar microwave photonic bandgap structures," Microw. Opt. Technol. Lett., Vol. 30, 15-19, Jul. 2001.

17. Park, J. S., J. H. Kim, J. H. Lee, S. H. Kim, and S. H. Myung, "A novel equivalent circuit and modeling method for defected ground structure and its application to optimization of a DGS lowpass filter," IEEE MTT-S Int. Dig., 417-420, 2002.

18. Boutejdar, A., "Compensating for DGS filter loss," Microwave and Communication Engineering, Magdeburg, Germany, 2012. 